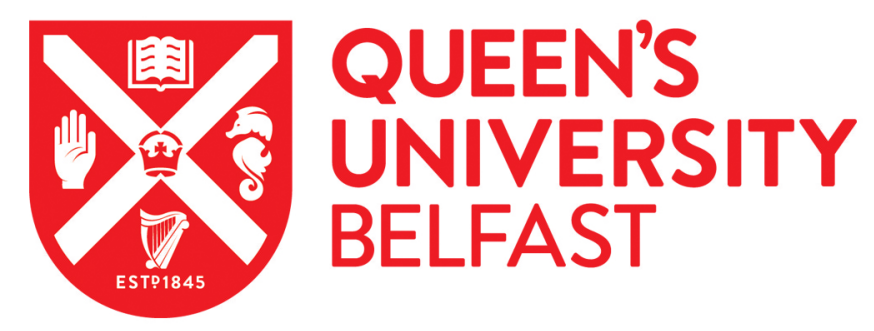

\title{
The antimicrobial effect of a commercial mixture of natural antimicrobials against Escherichia coli 0157:H7
}

Stratakos, A. C., Linton, M., Ward, P., Campbell, M., Kelly, C., Pinkerton, L., Stef, L., Pet, I., Stef, D., lancu, T., Theodoridou, K., Gundogdu, O., \& Corcionivoschi, N. (2019). The antimicrobial effect of a commercial mixture of natural antimicrobials against Escherichia coli O157:H7. Foodborne pathogens and disease, 16(2). https://doi.org/10.1089/fpd.2018.2465

Published in:

Foodborne pathogens and disease

Document Version:

Peer reviewed version

Queen's University Belfast - Research Portal:

Link to publication record in Queen's University Belfast Research Portal

Publisher rights

(c) 2018, Mary Ann Liebert, Inc. This work is made available online in accordance with the publisher's policies. Please refer to any applicable terms of use of the publisher.

\section{General rights}

Copyright for the publications made accessible via the Queen's University Belfast Research Portal is retained by the author(s) and / or other copyright owners and it is a condition of accessing these publications that users recognise and abide by the legal requirements associated with these rights.

Take down policy

The Research Portal is Queen's institutional repository that provides access to Queen's research output. Every effort has been made to ensure that content in the Research Portal does not infringe any person's rights, or applicable UK laws. If you discover content in the Research Portal that you believe breaches copyright or violates any law, please contact openaccess@qub.ac.uk. 


\section{The antimicrobial effect of a commercial mixture of natural antimicrobials against Escherichia coli 0157:H7}

Alexandros Ch. Stratakos 1,2 *, Mark Linton 1, Patrick Ward 2, Mairead Campbell 3, Carmel Kelly 1, Laurette Pinkerton 1, Lavinia Stef 4, Ioan Pet 4, Ducu Stef 4, Tiberiu lancu4, Katerina Theodoridou 3, Ozan Gundogdu5, Nicolae Corcionivoschi 1,4*

1 Agri-Food and Biosciences Institute, Veterinary Sciences Division, Bacteriology Branch, 12 Stoney Road, Belfast, BT4 3SD, Northern Ireland, United Kingdom

2 Auranta, Nova UCD, Belfield Innovation Park, Belfield, Dublin 4, Ireland

3 Institute for Global Food Security, School of Biological Sciences, Queen's University Belfast, Malone Road, BT95HN, Belfast, Northern Ireland.

4 Banat's University of Agricultural Sciences and Veterinary Medicine, King Michael I of Romania, Timisoara, Calea Aradului 119, 300645, Timisoara, Romania

5 Faculty of Infectious \& Tropical Diseases, London School of Hygiene and Tropical Medicine, Keppel Street, London, WC1E 7HT, UK

Key words: Escherichia coli 0157:H7, antimicrobial agents, virulence, rumen, antimicrobial mechanism

* Corresponding authors

Prof. Nicolae Corcionivoschi

Agri-Food and Biosciences Institute,

Veterinary Sciences Division,

Bacteriology Branch, 12 Stoney Road, Belfast, BT4 3SD,

Northern Ireland, United Kingdom.

Email address: Nicolae.Corcioniv/oschi@afbini.gov.uk

Dr Alexandros Ch. Stratakos

Agri-Food and Biosciences Institute,

Veterinary Sciences Division,

Bacteriology Branch, 12 Stoney Road, Belfast, BT4 3SD,

Northern Ireland, United Kingdom.

E-mail address: Alexandros.Stratakos@afbini.gov.uk 


\begin{abstract}
Ruminants are important reservoirs of E. coli O157: $\mathrm{H7}$ and are considered as the major source of the most foodborne outbreaks (e.g. 2017 outbreak in Germany, 2014 and 2016 outbreaks in U.S.A., all linked to beef products). A promising strategy to reduce $\mathrm{E}$. coli $\mathrm{O} 157$ is using antimicrobials to reduce the pathogen levels and/or virulence within the animal gastrointestinal tract and thus foodborne disease. The aim of the study was to determine the efficacy of a commercial mixture of natural antimicrobials against E. coli 0157 . The minimum inhibitory concentration and minimum bactericidal concentration of the antimicrobial were quantitatively determined and found to be 0.5 and $0.75 \%(\mathrm{v} / \mathrm{v})$ of the natural antimicrobial, respectively. Microbial growth kinetics were also employed to determine the effect of the antimicrobial on the pathogen. The natural antimicrobial affected the cell membrane of E. coli O157, as demonstrated by the increase in relative electric conductivity and increase in protein and nucleic acid release. The antimicrobial was also able to significantly reduce the concentration on E. coli 0157 in a model rumen system. Biofilm assays showed that sub-inhibitory concentrations of the antimicrobial significantly reduced the E. coli 0157 biofilm forming capacity without influencing pathogen growth. Also, the natural antimicrobial was able to reduce motility and exopolysaccharide production. Sub-inhibitory concentrations of the antimicrobial had no effect on Al-2 production. These findings suggest that the natural antimicrobial exerts an antimicrobial effect against $\mathrm{E}$. coli $\mathrm{O} 157$ in vitro and in a model rumen system and could be potentially used to control this pathogen in the animal gut. The results also indicate that sub-inhibitory concentrations of the antimicrobial effectively reduce biofilm formation, motility and exopolysaccharide production.
\end{abstract}

Introduction

Escherichia coli $0157: \mathrm{H7}$ is an important foodborne pathogen that has been linked to many outbreaks worldwide. Shiga toxins are major virulence factors of this pathogen and their production in the human gut along with other virulence factors can cause clinical manifestations that range in severity, even leading to life threatening hemolytic uremic syndrome (Luck et al. 2005; Smith et al. 2014). Ruminants, in particular cattle, are considered an important source of E. coli 0157:H7 most frequently colonising the lower gastrointestinal tract of cattle (Xu et al. 2014). Quantitative risk assessments have brought to light the association between levels of E. coli 0157:H7 in faeces and hides of cattle and the contamination of beef carcasses (Duffy et al. 2006). Treating patients with E. coli 0157 infection is problematic since many antibiotics are shown to enhance shiga toxin production in vitro and in vivo and thus increase the risk of hemolytic uremic syndrome development (Zhang et al. 2000). Owing to the potentially severe public health concerns, both researchers and industry are continuously investigating different strategies to control this pathogen. Different studies have sought to identify effective ways of reducing foodborne pathogens at pre-harvest and post-harvest stages including plant derived compounds, bacteriophages, vaccines and antimicrobial peptides (McDonnell et al. 2012; Shi et al. 2017; Zhang et al. 2000). However, the frequent foodborne disease outbreaks linked to meat and meat products demands further research. E. coli $\mathrm{O} 157$ cells are able to form complex aggregations which are enclosed in a matrix of exopolysaccharides (EPS) called biofilms. EPS plays a key role in the biofilm architecture and provides 
increased resistance to different types of stresses (e.g. host immune responses, osmotic and oxidative stresses antimicrobial agents) (Hentzer et al. 2003; Rivas et al. 2010; Silva et al. 2014). Quorum sensing (QS) constitutes a global regulatory mechanism for different physiological functions of $E$. coli as well as for virulence factors including biofilm formation (Sperandio et al. 2001). These virulence characteristics pose a significant challenge in clinical, veterinary and industry settings and identifying ways of controlling them are of great importance. It has been found that different natural plant extracts and compounds (e.g. carvacrol, brazilin) although they can be bactericidal, in sub-lethal concentrations can potentially increase the phenotypic expression of virulence and virulence gene expression of pathogenic E. coli (García-Heredia et al. 2016). Therefore, in addition to determining the bactericidal effect of different antimicrobial agents, it is also important to determine the effect of varying concentrations of these agents on virulence expression since these pathogens can be transferred, during the slaughter processs, from the animal gut to meat processing surfaces and meat, ultimately reaching the consumer.

There are no reliable commercially available strategies to control the carriage of E. coli 0157 in ruminants (Rivas et al. 2010).

The objectives of this pilot study were to determine the antimicrobial effect of a commercial mixture of natural antimicrobials against different strains of E. coli O157:H7. Also, to investigate its antimicrobial mechanism and also to determine its effect on motility, biofilm formation, exopolysaccharide production and quorum sensing at sub-inhibitory concentrations.

\section{Materials and Methods}

Bacterial strains and antimicrobial

E. coli 0157:H7 EDL 933 (ATCC43895), E. coli O157 VSD 400 and E. coli O157 PHL 09 were maintained in Tryptone Soya Agar plus $0.6 \%$ yeast extract (TSAYE, Oxoid, UK) slopes at $4^{\circ} \mathrm{C}$. When necessary the pathogens were cultured in Mueller-Hinton broth (MHB) at $37{ }^{\circ} \mathrm{C}$ for $24 \mathrm{~h}$. The antimicrobial product Auranta 3009 was obtained from Envirotech Innovative Products Ltd and consisted of lactic acid, E330 citric acid and citrus extract. The manufacturer of this product is Bio Science Nutrition Ireland Ltd, Ireland, DAFM No.IELK241361.

\section{Growth curves}

The three individual E. coli 0157 culture $(6.0 \mathrm{log} \mathrm{CFU} / \mathrm{ml}$ in MHB) were transferred into 96 well microtiter plates with final concentrations of the natural antimicrobial of $0,0.0625,0.125,0.25,0.5$ and $0.75 \%(\mathrm{v} / \mathrm{v})$. The inoculum level was determined after plating out onto MHA plates and incubation at $37^{\circ} \mathrm{C}$ for $24 \mathrm{~h}$. Cultures were incubated at $37^{\circ} \mathrm{C}$, and optical density was monitored at $600 \mathrm{~nm}$ at intervals of 1 hour, over $24 \mathrm{~h}$, using an automatic plate reader (FLUOstar Omega, BMG Labtech, U.K.). The concentrations of the antimicrobial that did not inhibit bacterial growth were chosen as the sub-inhibitory concentrations and used for the subsequent phenotypic virulence assays.

Minimum inhibitory concentration (MIC) and Minimum bactericidal concentrations (MBC)

In order to determine MIC and MBC we have used a methodology as previously described by Zhu et al. (2016). Briefly, the antimicrobial was diluted from $8 \%$ to $0.015 \%(v / v)$ in MHB. An overnight bacterial culture was diluted to approximately $6 \mathrm{Log} \mathrm{CFU} / \mathrm{mL}$ in MHB. A tube containing each dilution of the natural 
antimicrobial in MHB was inoculated with $5.49 \pm 0.16 \mathrm{log} \mathrm{CFU} / \mathrm{ml}$ of bacterial culture. Non-inoculated tubes were used as positive controls. Subsequently, the tubes were incubated at $37^{\circ} \mathrm{C}$ for $24 \mathrm{~h}$. The highest dilution of the natural antimicrobial in the tube without visible bacterial growth was considered as the MIC. To determine the MBC, $100 \mu$ of the cultures that showed no growth were spread plated onto Mueller-Hinton Agar (MHA) plates and incubated at $37^{\circ} \mathrm{C}$ for $24 \mathrm{~h}$.

Cell membrane permeability

E. coli $0157: \mathrm{H} 7$ cell membrane permeability was determined by assessing the electric conductivity of cultures treated with different concentrations of the natural antimicrobial for 2, 6 and $24 \mathrm{~h}$, as described by Stratakos et al. (2018). A conductivity meter (Jenway 4200, U.K.) was used to quantify changes in electric conductivity. Bacteria were washed with $5 \%$ glucose until their electric conductivity was near to that of $5 \%$ glucose (isotonic bacteria). The antimicrobial was added to $5 \%$ glucose $(0, \mathrm{MIC}, \mathrm{MBC})$ and the electric conductivities were measured (L1). The same concentrations of the antimicrobial were also prepared with the isotonic bacteria and the conductivities were measured after 2,6 and $24 \mathrm{~h}$ incubation at $37^{\circ} \mathrm{C}(\mathrm{L} 2)$. The conductivity of bacteria cells in $5 \%$ glucose treated in boiling water for 5 min was used (LO) as control. The permeability of cell membrane was calculated using the equation: Relative electric conductivity $(\%)=$ $100($ L2 - L1)/LO.

Membrane integrity

Membrane integrity for the three E. coli strains was evaluated in terms of protein leakage and $260 \mathrm{~nm}$ absorbing materials into the cell suspension as previously described (Stratakos et al. 2018), after a $6 \mathrm{~h}$ treatment with different concentrations of natural antimicrobial (0, MIC and MBC). The protein content in the supernatants was assessed using the Pierce BCA protein kit (ThermoScientific, U.K). Nucleic acid leakage in terms of optical density of $260 \mathrm{~nm}$ absorbing materials was performed using a UV-vis spectrophotometer (FLUOstar Omega, BMG Labtech, U.K.). Untreated samples were used as controls.

In vitro rumen assay

The antimicrobial efficiency of the natural antimicrobial (0, MIC, MBC and 2xMBC) against E. coli O157 EDL 933 was tested in the assay. Three dairy cows (Swedish-Red $\times$ Jersey/Holstein-Friesian) fitted with rumen cannula were used as rumen fluid donors. The rumen fluid was collected $3 \mathrm{~h}$ after the morning feeding. At the laboratory, the rumen contents (solid and liquid phases) were homogenised, filtered through four layers of cheesecloth and maintained at $39^{\circ} \mathrm{C}$ under anaerobic conditions. The filtered rumen fluid was dispensed into bottles and diluted with four parts of a buffer solution. The buffer solution was prepared by combining two solutions: buffer $A$ and buffer $B(5: 1)$. The following quantities were used to prepare one litre of buffer A: $10 \mathrm{~g} \mathrm{KH2PO} 4 ; 0.5 \mathrm{~g} \mathrm{MgSO} 4.7 \mathrm{H} 2 \mathrm{O} ; 0.5 \mathrm{~g} \mathrm{NaCl} ; 0.1 \mathrm{~g} \mathrm{CaCl} 2.2 \mathrm{H} 2 \mathrm{O}$ and $0.5 \mathrm{~g}$ Urea. One litre of buffer $B$ was prepared using the following: $15 \mathrm{~g} \mathrm{Na} 2 \mathrm{CO} 3$ and $1 \mathrm{~g} \mathrm{Na2S.9H2O}$. After mixing at 39oC, the combined buffer solution was adjusted to a final $\mathrm{pH}$ of 6.8. An overnight culture of E. coli 0157 was prepared and serially diluted in $9 \mathrm{ml}$ of PBS and inoculated into the rumen at approximately $6 \mathrm{Log} \mathrm{CFU} / \mathrm{ml}$. All bottles were flushed with $\mathrm{CO} 2$ for approximately $1 \mathrm{~min}$ prior to incubation at $39^{\circ} \mathrm{C}$, with agitation. Samples were taken from each bottle at 0, 4, 18 and $24 \mathrm{~h}$. After sampling at each time point, all bottles were flushed with $\mathrm{CO} 2$ for approximately $1 \mathrm{~min}$ before reincubation at $39^{\circ} \mathrm{C}$. For spread plating, $1 \mathrm{ml}$ aliquots taken from each bottle were serially diluted in $9 \mathrm{ml}$ volumes of MRD and $0.1 \mathrm{ml}$ aliquots of each dilution were spread onto plates of TSA which were incubated at $37^{\circ} \mathrm{C}$ for $2 \mathrm{~h}$. Subsequently, they were overpoured with CT-SMAC and incubated for another $48 \mathrm{~h}$ to allow for the recovery of injured cells. The 
suspected E. coli 0157 positive colonies were confirmed by latex agglutination (Prolex ${ }^{\mathrm{TM}}$ E. coli $\mathrm{O} 157$ Latex test reagent kit, Prolab Diagnostics, U.K.). Treatments and control samples (without antimicrobial addition) were incubated in triplicate. The assay was performed in duplicate, using fresh rumen fluid on two separate days.

Biofilm formation and motility assay

A biofilm formation assay for E. coli EDL 933 was performed in 96-well polystyrene plates according to the method described by Lee et al. (2014). Briefly, overnight cultures were inoculated into Luria-Bertani (LB) broth (Oxoid, U.K.) with known concentrations $(0,0.0625$ and $0.125 \%)$ of the antimicrobial and cultured for $24 \mathrm{~h}$ without shaking at $37^{\circ} \mathrm{C}$. To quantify biofilm formation, wells were washed three times with PBS to remove all non-adherent cells. Cells were fixed with $200 \mu \mathrm{l}$ of methanol for $20 \mathrm{~min}$. Biofilms were stained with crystal violet $(0.4 \%$ w.v) for 15 min and washed three times with PBS. The formed biofilm was then dissolved with $200 \mu \mathrm{l} 96 \%$ ethanol for $30 \mathrm{~min}$ and absorbance was measured $(570 \mathrm{~nm}$ ) in a microtiter plate reader. Cultures with no added antimicrobial served as positive controls. Motility was determined as described by Kulshreshtha et al. (2016). Briefly five microliters of E. coli 0157 culture ( 7.0 log CFU) were stabbed into plates with semisolid medium (MHB supplemented with $0.5 \%$ agar) with and without 0.0625 and $0.125 \%$ of the natural antimicrobial. Plates with no added antimicrobial served as positive controls.

Exopolysaccharide (EPS) content determination

An E. coli O157 EDL 933 culture grown in the presence and absence of sub-MIC of the antimicrobial was centrifuged and the supernatant was filtered through a $0.22 \mu \mathrm{m}$ filter. Three volumes of chilled $100 \%$ ethanol were added to the filtered supernatant and incubated overnight at $2^{\circ} \mathrm{C}$ to precipitate the EPS. The ethanol wash and centrifugation steps were repeated three times (Al-Shabib et al. 2016; Huston et al. 2004). EPS was quantified using the colorimetric phenol-sulphuric acid method as previously described (DuBois et al. 1956)

Autoinducer-2 (AI-2) assay

Todetermine whether Al-2 production in the E. coli 0157 EDL 933 is affected by sub-inhibitory concentrations of the novel antimicrobial, the autoinducer-2 (Al-2) assay was performed as previously described (Castillo et al. 2015; Duan and March 2010). Briefly, approximately 7 Log CFU/mL of E. coli 0157 were inoculated and cultured in LB broth with $0.5 \%(\mathrm{w} / \mathrm{v})$ glucose containing $0,0.0625$ and $0.125 \%$ of the antimicrobial at $37^{\circ} \mathrm{C}$ for $6 \mathrm{~h}$. Vibrio harveyi BB170 was grown overnight at $30^{\circ} \mathrm{C}$ with agitation in Autoinducer Bioassay medium (AB) and diluted 1:3,000. Cultures to be tested for CAl-1 activity were centrifuged $(12,000 \times \mathrm{g}$ for $5 \mathrm{~min})$. The supernatant was filtered and $20 \mu \mathrm{L}$ of cell-free supernatant was added to $80 \mu \mathrm{L}$ of diluted V. harveyi BB 170 reporter culture in a sterile 96 -well plate and incubated at $30^{\circ} \mathrm{C}$ with shaking at $500 \mathrm{rpm}$. The luminescence values of the samples were measured in an automatic plate reader (FLUOstar Omega, BMG Labtech, U.K.) every $0.5 \mathrm{~h}$. The analysis was repeated three times. In addition the E. coli cultures were enumerated by plating on brain-heart infusion agar. The aforementioned concentrations of the antimicrobial were also tested against growth of V. harveyi BB170 to ensure that decrease in bioluminescence was not caused by growth inhibition. 


\section{Statistical analysis}

All experiments were performed in triplicate. To measure the statistical significance we used two tailed Student's $t$ test. A group difference was assumed to be statistically significant when $P<0.05$. All results were expressed as means \pm S.D.

Results

Antimicrobial activity and mechanism

The antimicrobial exerted a potent effect against all E. coli $\mathrm{O} 157$ strains tested, with MIC and MBC values of 0.5 and $0.75 \%(\mathrm{v} / \mathrm{v})$ of the natural antimicrobial. The antimicrobial activity can be attributed to the lactic acid, citric acid and citrus extract present in the antimicrobial solution. The results revealed (Fig 1 ) that the electric conductivity of all treated samples increased significantly $(P<0.05)$ with exposure time $(2$ to $24 \mathrm{~h})$ and with increasing concentrations of the antimicrobial $(P<0.05)$. These results indicate that the gradual increase in cell membrane permeability leads to cellular leakage. Membrane integrity wasalso studied by monitoring protein (Fig. 2A) and nucleic acids release (Fig 2B) in terms of $260 \mathrm{~nm}$ absorbing materials. When the antimicrobial was applied at MIC and MBC levels, protein release was found to progressively increase with time $(P<0.05)$. Also, when the antimicrobial was applied at the $M B C$ level, protein release was significantly higher compared to the MIC treated E. coli O157. A very similar trend was observed for nucleic acid release (OD260nm). Application of the natural antimicrobial at MIC and MBC concentrations resulted in 5-12 fold increase in $260 \mathrm{~nm}$ materials release $(P<0.05)$ after $24 \mathrm{~h}$. There was also a gradual increase in the $260 \mathrm{~nm}$ materials release during the $24 \mathrm{~h}$ incubation, with the release of MBC treated cells being always higher compared to the MIC treatment $(P<0.05)$. Protein and nucleic acid release for control samples remained stable in all cases. The above results suggest that membrane structural damage is taking place at both MIC and MBC concentrations for all three E. coli 0157 strains tested. Since the three strains had the same MIC and MBC values and exhibited similar behaviour in terms of cell membrane integrity and permeability only E. coli EDL 933 was used in subsequent experiments as it is widely used in other studies thus allowing better comparisons.

Growth curves

Growth curves revealed complete inhibition of growth at MBC and MIC, as expected. The $1 / 2$ MIC $(0.25 \%$ $\mathrm{v} / \mathrm{v}$ ) concentrations caused a prolongation of the lag phase of all three E. coli 0157 strains tested for 1 hour whereas $1 / 4 \mathrm{MIC}(0.125 \% \mathrm{v} / \mathrm{v})$ and $1 / 8 \mathrm{MIC}(0.625 \% \mathrm{v} / \mathrm{v})$ showed a very similar growth curve to the control showing that theses concentrations had no effect on growth (Fig 3). Therefore these two concentrations were selected to study the effect on motility, biofilm formation, exopolysaccharide production and quorum sensing.

In vitro rumen system

Application of the antimicrobial at the MIC level did not influence the growth of the pathogen, which was very similar to the control $(P>0.05)$. Application at the $M B C$ level resulted in a gradual reduction in the $E$. coli 0157 counts, with the levels of the pathogen being significantly lower (5.15 $\pm 0.38 \log \mathrm{CFU} / \mathrm{ml})$ compared to the control and MIC treatment after $18 \mathrm{~h}$ of incubation (Fig 4). After $24 \mathrm{~h}$, the pathogen levels were reduced by $1.63 \log \mathrm{CFU} / \mathrm{ml}$ for the $\mathrm{MBC}$ treatment. The $2 \mathrm{xMBC}$ reduced the levels of $\mathrm{E}$. coli $\mathrm{O} 157$ by approx. 1 log CFU/ml within 4h, compared to the control and MIC treatments $(P<0.05)$. The pathogen 
levels were reduced by $3.15 \mathrm{log}$ CFU/ml after $24 \mathrm{~h}$, which was significantly lower compared to the pathogen levels at $24 \mathrm{~h}$ for the MBC treatment $(\mathrm{P}<0.05)$.

Effect on biofilm and motility

Addition of the natural antimicrobial at sub-inhibitory levels significantly decreased $(P<0.05)$ biofilm formation by E. coli O157, in a dose dependent manner by 43.20 and $52.13 \%$ compared to the control (Fig 5). The effect of the novel antimicrobial on the pathogen motility is shown in figure 6 . The natural antimicrobial at both sub-inhibitory concentrations resulted in a clear reduction in the motility of the pathogen $(34.11 \pm 3.95 \mathrm{~mm})$ compared to $68.77 \pm 5.50 \mathrm{~mm}$ for the control $(P<0.05)$.

Effect on EPS production

Spectrophotometric determination of the extracted EPS revealed that the concentration of EPS decreased when the antimicrobial was applied (Figure 7). A statistically significant reduction in the EPS production was recorded at both sub-inhibitory concentrations tested. The natural antimicrobial treated samples showed a $48.17 \pm 5.67$ and $52.07 \pm 11.50 \%$ reduction in EPS production. However, no difference was found between the two treatments $(\mathrm{P}<0.05)$.

\section{Effect on Quorum sensing}

The effect of the natural antimicrobial on Al-2 production by E. coli $0157: \mathrm{H} 7$ was assayed using the $\mathrm{V}$. harveyi BB170 reporter strain. The reporter strain is bioluminescent in response to the presence of Al-2. Results showed that a six-hour treatment of $\mathrm{E}$. coli $\mathrm{O} 157: \mathrm{H} 7$ with sub-inhibitory concentrations of the antimicrobial did not result in any significant changes $(P<0.05)$ in Al-2 production compared to the control (Fig. 8A). The antimicrobial at the concentrations used $(0.0625$ and $0.125 \%)$ did not have any effect on the growth of E. coli $\mathrm{O} 157$ (Fig. 8B). Also, the antimicrobial showed no antimicrobial activity against $\mathrm{V}$. harveyi at the concentrations used in this study (results not shown).

\section{Discussion}

Enterohemorrhagic E. coli $0157: \mathrm{H} 7$ infection is a worldwide problem linked to many foodborne outbreaks (Vygen-Bonnet et al. 2017; CDC 2018). Since ruminants are an important source of this pathogen (EFSA 2010), reducing its ability to reside in the animal gastrointestinal tract would be desirable. In the present study we demonstrated that the natural antimicrobial is effective against E. coli O157:H7 with MIC and $\mathrm{MBC}$ values of 0.5 and $0.75 \%(\mathrm{v} / \mathrm{v})$, respectively.

When bacteria are exposed to antimicrobial agents, different physical changes occur to their cell membranes (Bajpai et al. 2013). We show that the bactericidal effect observed is linked to the ability of the antimicrobial to disrupt E. coli O157:H7membranes as described in figure 1. This indicates a potential leakage of ions even at the MIC level because the bacterial membrane acts as a barrier to the movement of electrolytes that take part in cell functions and metabolism (Diao et al. 2014). Different studies have investigated the effect of plant extracts on E. coli 0157. Exposing E. coli $\mathrm{O} 157$ to eugenol has also been observed to cause membrane damage and subsequent leakage of intracellular components (Di Pasqua et al. 2007).

Commercial citrus fruit extracts have also been found to cause physical damage to Salmonella enterica and E. coli membranes and leakage of cellular materials (Alvarez-Ordonez et al. 2013). 
Stratakos et al. (2018) also found that carvacrol was able to increase cell membrane permeability in different STEC strains leading to cell death. Release of proteins and nucleic acids ( $260 \mathrm{~nm}$ absorbing materials) is used as an indirect way to assess membrane damage after application of an antimicrobial treatment (Bajpai et al. 2013; Stratakos et al. 2018). The natural antimicrobial caused a rapid release of proteins and $260 \mathrm{~nm}$ absorbing material, which increased over time, suggesting damage to the cytoplasmic membrane of the pathogen, which is consistent with the increase in relative electric conductivity. Zhang et al. (2017) also observed a dose dependent increase (0, MIC, 2xMIC) in the protein and nucleic acid release of non-pathogenic E. coli cells after treatment with black pepper essential oil. Carvacrol and cinnamon essential oil has also been found to cause protein and nucleic acid release in E. coli and Staphylococcus aureus (Zhang et al. 2016). In general, the novel antimicrobial was found to interfere with E. coli $\mathrm{O} 157$ ion homeostasis and membrane integrity.

The in vitro rumen model showed that it is possible to reduce E. coli 0157 EDL 933 shedding in ruminants with the natural antimicrobial. The $2 \mathrm{xMBC}$ was used in the experimental design as it has been found in other studies that antimicrobials exhibit significantly reduced activity when applied in complex systems since these systems can contain different inhibitors (Burt 2004; Rydlo et al. 2006). McDonnell et al. (2012) found that although caseicin A was able to reduce E. coli 0157 in a broth system the same concentrations $(\geq 2 \mathrm{mg} / \mathrm{ml}$ ) had no effect when applied in an in vitro model system. The study of Rivas et al. (2010) showed that carvacrol applied at a concentration of $1000 \mu \mathrm{g} / \mathrm{ml}$ reduced E. coli 0157 by $>5 \log \mathrm{CFU} / \mathrm{ml}$ in an in vitro rumen system after $24 \mathrm{~h}$ incubation. However, more work is required to elucidate further the effects of the antimicrobial on rumen microbiota and thus rumen fermentation.

It is possible that during ingestion of an antimicrobial present in the feed or water, its concentrations can be reduced due to partial inactivation when coming in contact with other compounds in the animal digestive system or simply by dilution. These lower concentrations might not have an effect on growth of pathogens residing in the gut but can potentially have an effect on different virulence factors (GarcíaHeredia et al. 2016). Although a potential increase in the virulence of the pathogen due to exposure to sub-inhibitory concentrations of the antimicrobial will not cause any clinical symptoms to the animal, it could potentially result in cells with increased virulence being transferred to the meat or food producing surfaces during the slaughter process, increasing the risk and/or severity of human infection. Therefore, the present study also investigated the effect of sub-inhibitory concentrations of the antimicrobial on different virulence factors of E. coliO157:H7.

E. coli $\mathrm{O} 157$ is also able to form biofilms on various biotic and abiotic surfaces. These biofilms are resistant to host immune responses, antimicrobial agents and other stresses (Kim et al. 2016). Therefore, subinhibitory concentrations of the natural antimicrobial were used to investigate the effect on biofilm formation. Both concentrations used $(0.0625$ and $0.152 \%)$ reduced $\mathrm{E}$. coli $\mathrm{O} 157$ biofilm formation in a dose dependent manner without affecting the growth of planktonic cells (Fig. 5) Previously, eugenol was found to inhibit biofilm formation by Listeria monocytogenes and E. coli 0157 (Perez-Conesa et al. 2006; Upadhyay et al. 2013). Similarly, sub-inhibitory concentrations of citral have been found to inhibit Cronobacter sakazakii biofilm formation at $12^{\circ} \mathrm{C}$ and $25^{\circ} \mathrm{C}$ (Shi et al. 2017). Carvacrol has also been found to inhibit biofilm formation in Campylobacter jejuni (Burt et al. 2014).

Motility plays animportant role in E. coli biofilm formation (Ren et al. 2001) and also contributes to colonisation of host tissues and enables pathogens to move towards favourable environments and away from repellents (Zhu et al. 2015). Therefore, the motility of E. coli O157:H7 during exposure to sub- 
inhibitory concentrations of the antimicrobial was also investigated. Both sub-inhibitory concentrations of the antimicrobial significantly reduced the motility of the pathogen (Fig. 6). The presence of functioning flagella is required for motility and biofilm formation in Gram-negative bacteria (Chelvam et al. 2014). Burt et al. (2016) showed that organic acids, specifically cinnamic $(0.2 \%)$, lactic $(0.6 \%)$ and propionic acid $(0.4 \%)$ can reduce motility in Salmonella typhimurium. Mith et al. (2015) also found that oregano essential oil and carvacrol are able to significantly down-regulate genes involved in motility of E. coli O157:H7. Carvacrol has also been found, after overnight incubation, to prevent the development of flagella in E. coli O157:H7 leading to aflagellate and non-motile cells. Coumarins were also found to supress curli genes and motility genes by causing reductions in fimbriae production and swarming motility in E. coli 0157:H7 (Lee et al. 2014). Thus, a possible explanation for the reduced motility observed is inhibition of the flagellar synthesis by the sub-inhibitory concentrations of the antimicrobial.

To further elucidate the effect on E. coli 0157:H7 virulence, EPS production by treated and non-treated bacteria was determined. E. coli 0157:H7 produces EPS which acts as a physical barrier to protect cells against different stresses. EPS is also involved in cell adhesion and the formation of three-dimensional biofilm structures (Ryu and Beuchat 2005). Therefore, any changes in the EPS production by the pathogen can have an effect on biofilm formation and architecture and also reduce resistance to drugs. In this study our results revealed that EPS was reduced significantly and to the same extent by the two sub-inhibitory concentrations of the antimicrobial (Fig. 7). The study of Al-Shabib et al. (2016) also showed that EPS was reduced significantly when Listeria monocytogenes and E. coli were treated with sub-inhibitory concentrations of zinc oxide nanostructures from Nigella sativa. Cellulose is one of the EPS components that enable biofilm formation in Enterobacteriaceae (Priester et al. 2006). Shi et al. (2017) found that treating Cronobacter sakazakii cells with citral down-regulated the expression of bcsA and bcsG that encode the cellulose biosynthesis operon. In the present study, we hypothesise that the novel antimicrobial could potentially affect the synthesis of components (e.g. cellulose) which EPS consists of and thus lead to inhibition of E. coli O157:H7 biofilm formation.

Accordingly our results showed that sub-inhibitory concentrations of the novel antimicrobial can reduce the pathogen's biofilm forming capability, motility and exopolysaccharide production. The data also suggest that the antimicrobial does not interfere with the Al- 2 synthetic pathway and thus the anti-biofilm effect of the antimicrobial is not closely linked to Al-2 production.

\section{Conclusion}

Our study showed that the natural antimicrobial has a potent antimicrobial effect against all tested E. coli 0157:H7 strains and exerts its antimicrobial effect by cell membrane disruption. Our data also shows that the antimicrobial can reduce the levels of the pathogen in an in vitro rumen model and revealed that subinhibitory concentrations of the antimicrobial attenuate E. coli 0157:H7 reduced biofilm formation, motility and exopolysaccharide production, potentially reducing the risk and severity of disease. However, expression of virulence could be influenced by other factors during the slaughter process which should be also investigated in the future. Future studies should also elucidate the effect of the antimicrobial on Shiga toxin production as it is one of the main E. coli 0157:H7 virulence factors. These findings indicate that the natural antimicrobial can potentially be used as an antimicrobial toreduce the presence of E. coli O157:H7 in the gastrointestinal tract of ruminants and help control human infection.

Acknowledgements 
This study was supported by a grant awarded to NC and AS by Envirotech Innovative Products Ltd. Funders had no role in study design, data collection, analysis, interpretation and publication.

Figure legends

Figure 1. Effect of different concentrations of the antimicrobial on the three E. coli O157:H7 strains cell permeability as determined by measuring changes in relative electric conductivity. Each point represents the mean \pm standard deviation. MIC: minimum inhibitory concentration; MBC: minimum bactericidal concentration.

Figure 2. Effect of different concentrations of the antimicrobial on the three E. coli O157:H7 strains protein (A) and nucleic acid release (B). Each point represents the mean \pm standard deviation. MIC: minimum inhibitory concentration; MBC: minimum bactericidal concentration.

Figure 3. Growthof E. coli 0157:H7 EDL 933 (A), VSD 400 (B) and PHL 09 (C) in MHA with various concentrations of the antimicrobial. Each value represents the mean of three different measurements.

Figure 4. Levels of E. coli O157:H7 EDL 933 following treatment with different concentrations of the antimicrobial in an in vitro rumen system. Each point represents the mean \pm standard deviation.

Figure 5. Effect of different sub-inhibitory concentrations of the antimicrobial on biofilm formation of $\mathrm{E}$. coli 0157:H7 EDL 933. Each point represents the mean \pm standard deviation.

Figure 6. Effect of different sub-inhibitory concentrations of the antimicrobial on E. coli O157:H7 EDL 933 motility. Each point represents the mean \pm standard deviation.

Figure 7. Quantitative determination of EPS inhibition E. coli O157:H7 EDL 933 after exposure to different sub-inhibitory concentrations of the antimicrobial. Each point represents the mean \pm standard deviation. Results are expressed in percentages of the control treatment.

Figure 8. Production of the autoinducer (AI-2) by E. coli O157:H7 EDL 933 after exposure to different subinhibitory concentrations of the antimicrobial (A). Levels of E. coli 0157:H7 EDL 933 after exposure to different sub-inhibitory concentrations of the antimicrobial (B). Each point represents the mean \pm standard deviation.

References

Al-Shabib N.A., Husain F.M., Ahmed F., et al. . Biogenic synthesis of Zinc oxide nanostructures from Nigella sativa seed: Prospective role as food packaging material inhibiting broad-spectrum quorum sensing and biofilm. Scientific reports 2016; 6:36761.

Alvarez-Ordonez A., Carvajal A., Arguello H., Martinez-Lobo F.J., Naharro G. and Rubio P.Antibacterial activity and mode of action of a commercial citrus fruit extract. Journal of applied microbiology 2013; 115:50-60.

Bajpai V.K., Sharma A. and Baek K.-H. Antibacterial mode of action of Cudrania tricuspidata fruit essential oil, affecting membrane permeability and surface characteristics of food-borne pathogens. Food Control 2013; 32:582-590 PubMed.

Burt S. Essential oils: their antibacterial properties and potential applications in foods-a review. International journal of food microbiology 2004; 94:223-253. 
Burt S.A., Adolfse S.J., Ahad D.S., et al. . Cinnamaldehyde, Carvacrol and Organic Acids Affect Gene Expression of Selected Oxidative Stress and Inflammation Markers in IPEC-J2 Cells Exposed to Salmonella typhimurium. Phytotherapy Research 2016; 30:1988-2000.

Burt S.A., Ojo-Fakunle V.T., Woertman J. and Veldhuizen E.J. The natural antimicrobial carvacrol inhibits quorum sensing in Chromobacterium violaceum and reduces bacterial biofilm formation at sub-lethal concentrations. PLoS One 2014; 9:e93414.

Castillo S., Heredia N. and García S. 2 (5H)-Furanone, epigallocatechin gallate, and a citric-based disinfectant disturb quorum-sensing activity and reduce motility and biofilm formation of Campylobacter jejuni. Folia microbiologica 2015; 60:89-95.

CDC. Center for Disease Control and Prevention. Reports on selected E. coli investigations. https://www.cdc.gov/ecoli/outbreaks.html. Accessed 11/8/18.

Chelvam K.K., Chai L.C. and Thong K.L. Variations in motility and biofilm formation of Salmonella enterica serovar Typhi. Gut pathogens 2014; 6:2.

Di Pasqua R., Betts G., Hoskins N., Edwards M., Ercolini D. and Mauriello G. Membrane toxicity of antimicrobial compounds from essential oils. Journal of agricultural and food chemistry 2007; $55: 4863-$ 4870 .

Diao W.-R., Hu Q.-P., Zhang H. and Xu J.-G. Chemical composition, antibacterial activity and mechanism of action of essential oil from seeds of fennel (Foeniculum vulgare Mill.). Food Control 2014; 35:109-116 PubMed.

Duan F. and March J.C. Engineered bacterial communication prevents Vibrio cholerae virulence in an infant mouse model. Proceedings of the National Academy of Sciences 2010; 107:11260-11264.

DuBois M., Gilles K.A., Hamilton J.K., Rebers P.t. and Smith F. Colorimetric method for determination of sugars and related substances. Analytical chemistry 1956; 28:350-356.

Duffy G., Cummins E., Nally P., O'Brien S. and Butler F. A review of quantitative microbial risk assessment in the management of Escherichia coli 0157: $\mathrm{H} 7$ on beef. Meat science 2006; 74:76-88 PubMed .

EFSA. The European Summary report on trends and sources of zoonoses and zoonotic agents and foodborne outbreaks in the European Union in 2008. EFSA Journal 2010; 8:1496.

García-Heredia A., García S., Merino-Mascorro J.Á., Feng P. and Heredia, N., 2016. Natural plant products inhibits growth and alters the swarming motility, biofilm formation, and expression of virulence genes in enteroaggregative and enterohemorrhagic Escherichia coli. Food microbiology 2016, 59: 124-132.

Hentzer M., Wu H., Andersen J.B., et al. . Attenuation of Pseudomonas aeruginosa virulence by quorum sensing inhibitors. The EMBO journal 2003; 22:3803-3815 PubMed.

Huston A.L., Methe B. and Deming J.W. Purification, characterization, and sequencing of an extracellular cold-active aminopeptidase produced by marine psychrophile Colwellia psychrerythraea strain $34 \mathrm{H}$. Applied and environmental microbiology 2004; 70:3321-3328. 
Kim Y.-G., Lee J.-H., Gwon G., Kim S.-I., Park J.G. and Lee J. Essential oils and eugenols inhibit biofilm formation and the virulence of Escherichia coli O157: H7. Scientific reports 2016; 6:36377.

Kulshreshtha G., Borza T., Rathgeber B., et al. . Red seaweeds Sarcodiotheca gaudichaudii and Chondrus crispus down regulate virulence factors of Salmonella Enteritidis and induce immune responses in Caenorhabditis elegans. Frontiers in microbiology 2016; 7.

Lee J.-H., Kim Y.-G., Cho H.S., Ryu S.Y., Cho M.H. and Lee J. Coumarins reduce biofilm formation and the virulence of Escherichia coli 0157: H7. Phytomedicine 2014; 21:1037-1042 PubMed .

Luck S.N., Bennett-Wood V., Poon R., Robins-Browne R.M. and Hartland E.L. Invasion of epithelial cells by locus of enterocyte effacement-negative enterohemorrhagic Escherichia coli. Infect Immun 2005; 73:3063-71 PubMed .

McDonnell M.J., Rivas L., Burgess C.M., Fanning S. and Duffy G. Inhibition of verocytotoxigenic Escherichia coli by antimicrobial peptides caseicin $A$ and $B$ and the factors affecting their antimicrobial activities. International journal of food microbiology 2012; 153:260-268.

Mith H., Clinquart A., Zhiri A., Daube G. and Delcenserie V. The impact of oregano (Origanum heracleoticum) essential oil and carvacrol on virulence gene transcription by Escherichia coli 0157: H7. FEMS microbiology letters 2015; 362:1-7.

Perez-Conesa D., McLandsborough L. and Weiss J. Inhibition and inactivation of Listeria monocytogenes and Escherichia coli O157: H7 colony biofilms by micellar-encapsulated eugenol and carvacrol. Journal of food protection 2006; 69:2947-2954.

Priester J.H., Olson S.G., Webb S.M., Neu M.P., Hersman L.E. and Holden P.A. Enhanced exopolymer production and chromium stabilization in Pseudomonas putida unsaturated biofilms. Applied and Environmental Microbiology 2006; 72:1988-1996.

Rasko D.A. and Sperandio V. Anti-virulence strategies to combat bacteria-mediated disease. Nature reviews Drug discovery 2010; 9:117-128.

Ren D., Sims J.J. and Wood T.K. Inhibition of biofilm formation and swarming of Escherichia coli by (5Z)-4bromo-5-( PubMed bromomethylene)-3-butyl-2 (5H)-furanone. Environmental Microbiology 2001; 3:731736.

Rivas L., McDonnell M.J., Burgess C.M., et al. . Inhibition of verocytotoxigenic Escherichia coli in model broth and rumen systems by carvacrol and thymol. International journal of food microbiology 2010; 139:70-78.

Rydlo T., Rotem S. and Mor A. Antibacterial properties of dermaseptin S4 derivatives under extreme incubation conditions. Antimicrobial agents and chemotherapy 2006; 50:490-497.

Ryu J.-H. and Beuchat L.R. Biofilm formation by Escherichia coli 0157: H7 on stainless steel: effect of exopolysaccharide and curli production on its resistance to chlorine. Applied and environmental microbiology 2005; 71:247-254.

Shi C., Sun Y., Liu Z., et al. . Inhibition of Cronobacter sakazakii Virulence Factors by Citral. Scientific Reports 2017; 7:43243. 
Silva V.O., Soares L.O., Júnior A.S., Mantovani H.C., Chang Y.-F. and Moreira M.A.S. Biofilm formation on biotic and abiotic surfaces in the presence of antimicrobials by Escherichia coli Isolates from cases of Bovine mastitis. Applied and environmental microbiology 2014; 80:6136-6145.

Smith J.L., Fratamico P.M. and Gunther N. Shiga toxin-producing Escherichia coli. Adv Appl Microbiol 2014; 86:97.

Sperandio V., Torres A.G., Girón J.A. and Kaper J.B. Quorum sensing is a global regulatory mechanism in enterohemorrhagic Escherichia coli O157: H7. Journal of bacteriology 2001; 183:5187-5197.

Stratakos A.C., Sima F., Ward P., et al. . The in vitro effect of carvacrol, a food additive, on the pathogenicity of 0157 and non-0157 Shiga-toxin producing Escherichia coli. Food Control 2018; 84:290-296 PubMed .

Upadhyay A., Upadhyaya I., Kollanoor-Johny A. and Venkitanarayanan K. Antibiofilm effect of plant derived antimicrobials on Listeria monocytogenes. Food microbiology 2013; 36:79-89 PubMed .

Vygen-Bonnet, S., Rosner, B., Wilking, H., Fruth, A., Prager, R., Kossow, A., Lang, C., Simon, S., Seidel, J., Faber, M. and Schielke, A., 2017. Ongoing haemolytic uraemic syndrome (HUS) outbreak caused by sorbitol-fermenting (SF) Shiga toxin-producing Escherichia coli (STEC) 0157, Germany, December 2016 to May 2017. Eurosurveillance 2017; 22:30541.

Xu Y., Dugat-Bony E., Zaheer R., et al. . Escherichia coli 0157: H7 super-shedder and non-shedder feedlot steers harbour distinct fecal bacterial communities. PloS one 2014; 9:e98115.

Zhang J., Ye K.-P., Zhang X., Pan D.-D., Sun Y.-Y. and Cao J.-X. Antibacterial activity and mechanism of action of black pepper essential oil on meat-borne Escherichia coli. Frontiers in microbiology 2017; 7:2094.

Zhang X., McDaniel A.D., Wolf L.E., Keusch G.T., Waldor M.K. and Acheson D.W. Quinolone antibiotics induce Shiga toxin-encoding bacteriophages, toxin production, and death in mice. The Journal of infectious diseases 2000; 181:664-670.

Zhang Y., Liu X., Wang Y., Jiang P. and Quek S. Antibacterial activity and mechanism of cinnamon essential oil against Escherichia coli and Staphylococcus aureus. Food Control 2016; 59:282-289 PubMed .

Zhu H., Du M., Fox L. and Zhu M.-J. Bactericidal effects of Cinnamon cassia oil against bovine mastitis bacterial pathogens. Food Control 2016; 66:291-299 PubMed .

Zhu M., Olsen S., Sheng L., Xue Y. and Yue W. Antimicrobial efficacy of grape seed extract against Escherichia coli 0157: H7 growth, motility and Shiga toxin production. Food Control 2015; 51:177-182 PubMed.

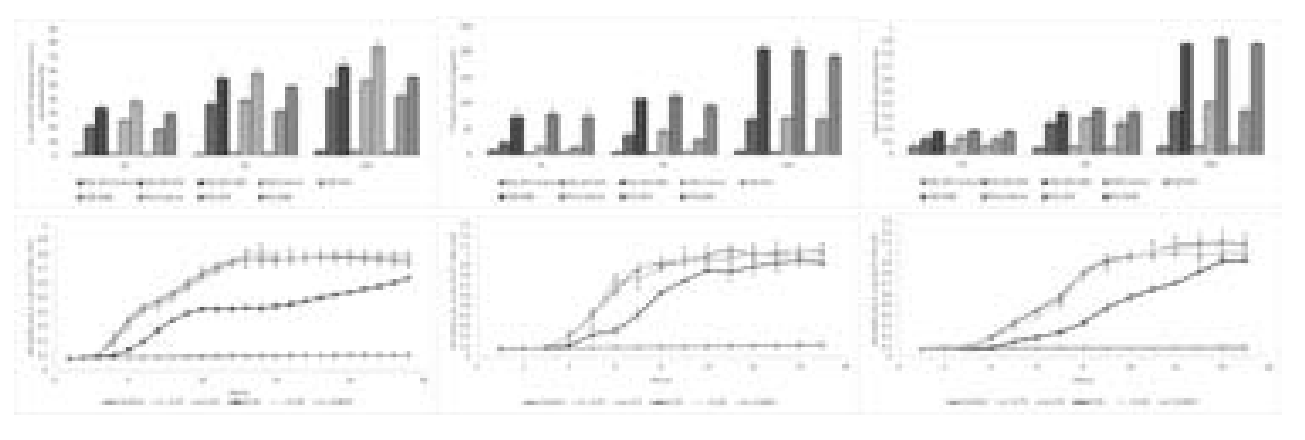




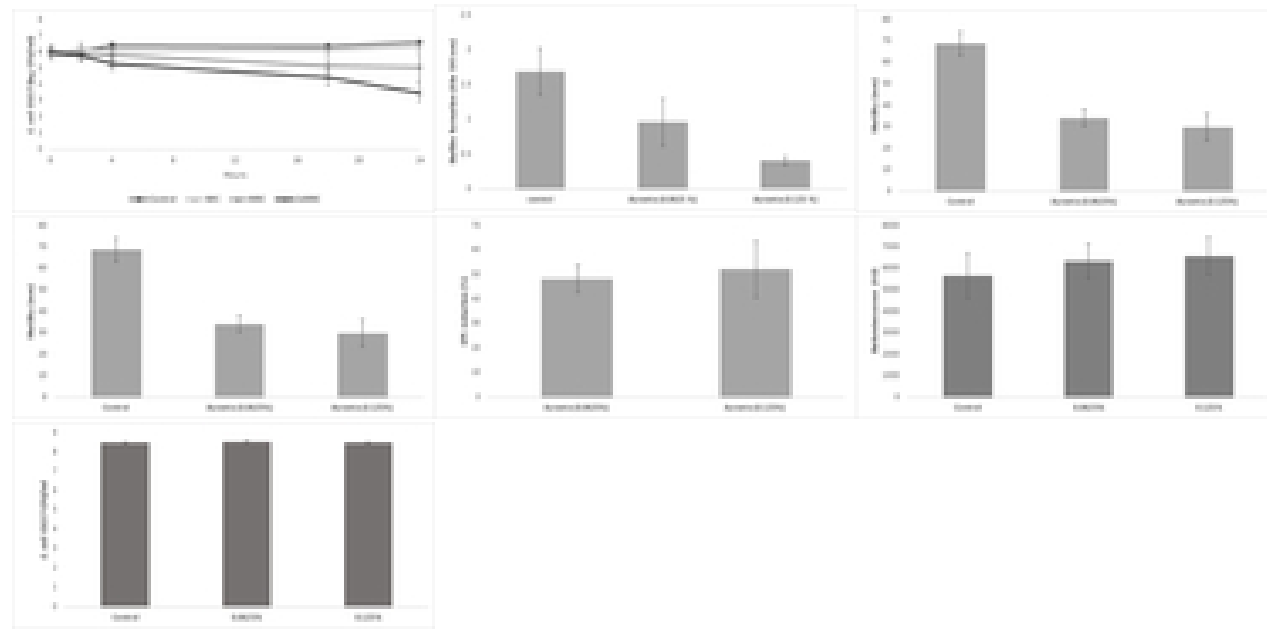

